\title{
Impact of experimental type 1 diabetes mellitus on systemic and coagulation vulnerability in mice acutely exposed to diesel exhaust particles
}

\author{
Abderrahim Nemmar ${ }^{1 *}$, Deepa Subramaniyan ${ }^{1}$, Javed Yasin $^{2}$ and Badreldin $\mathrm{H} \mathrm{Ali}^{3}$
}

\begin{abstract}
Background: Epidemiological evidence indicates that diabetic patients have increased susceptibility to adverse cardiovascular outcomes related to acute increases in exposures to particulate air pollution. However, mechanisms underlying these effects remain unclear.

Methods: To evaluate the possible mechanisms underlying these actions, we assessed the systemic effects of diesel exhaust particles (DEP) in control mice, and mice with streptozotocin-induced type 1 diabetes. Four weeks following induction of diabetes, the animals were intratracheally instilled (i.t.) with DEP $(0.4 \mathrm{mg} / \mathrm{kg})$ or saline, and several cardiovascular endpoints were measured $24 \mathrm{~h}$ thereafter.

Results: DEP caused leukocytosis and a significant increase in plasma C-reactive protein and 8-isoprostane concentrations in diabetic mice compared to diabetic mice exposed to saline or non-diabetic mice exposed to DEP. The arterial $\mathrm{PO}_{2}$ as well as the number of platelets and the thrombotic occlusion time in pial arterioles assessed in vivo were significantly decreased following the i.t. instillation of DEP in diabetic mice compared to diabetic mice exposed to saline or non-diabetic mice exposed to DEP. Both alanine aminotransferase and aspartate transaminase activities, as well as the plasma concentrations of plasminogen activator inhibitor and von Willebrand factor were significantly increased in DEP-exposed diabetic mice compared to diabetic mice exposed to saline or DEP-exposed non-diabetic mice. The in vitro addition of DEP $(0.25-1 \mu \mathrm{g} / \mathrm{ml})$ to untreated mouse blood significantly and dose-dependently induced in vitro platelet aggregation, and these effects were exacerbated in blood of diabetic mice.

Conclusion: This study has shown that systemic and coagulation events are aggravated by type 1 diabetes in mice, acutely exposed to DEP and has described the possible mechanisms for these actions that may also be relevant to the exacerbation of cardiovascular morbidity accompanying particulate air pollution in diabetic patients.
\end{abstract}

Keywords: Air pollution, Diesel exhaust particles, Streptozotocin, Type 1 diabetes, Thrombosis, Platelet aggregation, Mice

\section{Background}

Large body of epidemiological studies have suggested a linkage between particulate air pollution and increased cardiovascular morbidity and mortality [1,2]. Associations between particulate matter with a diameter $\leq 2.5 \mu \mathrm{m}\left(\mathrm{PM}_{2.5}\right)$ and mortality exists even at low concentrations of air pollutants $[1,2]$. These epidemiological observations have demonstrated that particles not only exert respiratory effects, but also increase cardiovascular morbidity and mortality $[1,2]$.

\footnotetext{
* Correspondence: anemmar@uaeu.ac.ae

'Departments of Physiology, College of Medicine and Health Sciences, United Arab Emirates University, P.O. Box 17666, Al Ain, Unite Arab Emirates Full list of author information is available at the end of the article
}

An important feature of the epidemiological associations between air pollution and morbidity or mortality is that the acute adverse effects of particulate air pollution appear to be most marked in people with underlying cardiovascular disease, or risk factors such as diabetes mellitus. Indeed, several studies have reported that patients with diabetes mellitus have increased susceptibility to adverse cardiovascular outcomes related to acute increases in exposures to air pollution [3-5].

The vast majority of cases of diabetes are categorized into two broad groups. Type 1 diabetes (known as insulin-dependent diabetes or juvenile-onset diabetes) which is caused by a complete deficiency of insulin

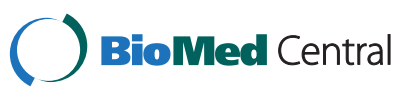


secretion resulting from a cellular-mediated autoimmune destruction of the $\beta$ cells of the pancreas. This form represents about $10 \%$ of all forms of diagnosed diabetes. Type 2 diabetes which is much more prevalent (90\%) is caused by a combination of resistance to insulin action and an inadequate compensatory insulin secretory response [6,7]. It is well known that cardiovascular complications including thrombosis constitute the major cause of morbidity and mortality in both type 1 and type 2 diabetes [7].

While several studies using type 2 animal model of diabetes have been performed to verify whether or not, and to what extent are the cardiovascular effects of exposure to particulate air pollution exaggerated, experimental studies investigating the effect of particles on animal model of type 1 diabetes are very limited. In relation to type 2 model of diabetes, it has been demonstrated that chronic exposure to $\mathrm{PM}_{2.5}$ in high-fat-fed nonatherosclerotic $\mathrm{C} 57$ mice aggravates insulin resistance by enhancing inflammation in adipose tissue [8]. More recently, it has been demonstrated that long-term exposure to $\mathrm{PM}_{2.5}$ causes glucose intolerance, insulin resistance and inflammation $[9,10]$. However, using type 1 model of diabetes, as far as we are aware, only one study has reported an aggravation in the increase of 8-Oxo-2'-deoxyguanosine (8-OHdG), a marker of oxidative stress, and endothelin-1 in streptozotocin (STZ)-induced type 1 diabetes in rats compared to non-diabetic ones following the exposure to particulate air pollution [11]. There have been no previous experimental studies on the acute effects of particulate air pollution on coagulation in animal model of type 1 diabetes.

We have recently demonstrated that diesel exhaust particle (DEP) equally increased airway resistance and caused lung inflammation in both STZ-diabetic and nondiabetic mice. However, the occurrence of pulmonary oxidative stress and presence of apoptosis were only seen in DEP-exposed diabetic mice, suggesting that diabetes increased susceptibility to particulate air pollution [12]. In the present study, we aimed at quantifying the effects of pulmonary exposure to DEP in mice on cardiovascular parameters including pial arteriolar thrombosis in vivo, platelet aggregation in vitro, some markers of inflammation, oxidative stress and fibrinolysis in a mouse model of type 1 diabetes.

\section{Results}

\section{General characteristic of the diabetic-STZ and non-diabetic} mice

The mean body weight in diabetic mice $(25.0 \pm 1.8 \mathrm{~g})$ was significantly $(\mathrm{P}<0.001)$ lower than that of nondiabetic mice $(31.6 \pm 1.7 \mathrm{~g})$. The mean blood glucose level was significantly $(\mathrm{P}<0.001)$ increased in diabetic mice $(557 \pm 62.2 \mathrm{mg} / \mathrm{dL})$ compared to that of non-diabetic mice $(130.0 \pm 6.9 \mathrm{mg} / \mathrm{dL})$.
Effect of DEP on systemic inflammation and oxidative stress Figure 1A shows that in diabetic mice, pulmonary exposure to DEP causes leukocytosis. The leukocyte numbers were increased in diabetic mice exposed to DEP compared to diabetic mice exposed to saline or non-diabetic mice exposed to DEP.

The plasma concentration of c-reactive protein (CRP) was significantly increased following DEP exposure in diabetic mice compared to diabetic mice exposed to saline or non-diabetic mice exposed to DEP (Figure 1B).

The concentration of 8-isoprostane, a marker of oxidative stress, was significantly increased after the pulmonary exposure to DEP in diabetic mice versus diabetic mice exposed to saline or non-diabetic mice exposed to DEP (Figure 1C).

\section{Effect of DEP on arterial $\mathrm{PO}_{2}$ and $\mathrm{PCO}_{2}$}

In non-diabetic mice, i.t. instillation of DEP did not affect the $\mathrm{PaO}_{2}$. The decrease in $\mathrm{PaO} 2$ was not statistically significant between non-diabetic + saline versus diabetic + saline mice. Interestingly, the $\mathrm{PaO}_{2}$ was significantly decreased in diabetic mice exposed to DEP compared to diabetic mice exposed to saline or non-diabetic mice exposed to DEP (Figure 2A). No difference in the $\mathrm{PaCO}_{2}$ was found between the 4 different groups (Figure 2B).

\section{Effect of DEP on alanine aminotransferase (ALT) and aspartate transaminase (AST) activities in plasma}

In non-diabetic mice, DEP administration did not affect the plasma activities of AST and ALT compared to salineexposed mice. No difference in the enzyme activities was found between saline-treated diabetic and saline-treated non-diabetic mice. However, the AST and ALT activities were increased in DEP-exposed diabetic mice compared to diabetic mice exposed to saline or DEP-exposed nondiabetic mice (Figure 3).

\section{Effect of DEP on circulating platelet numbers and photochemically-induced thrombosis in pial arterioles}

Figure 4A shows that in non-diabetic mice, DEP administration did not affect the number of circulating platelets compared to saline-exposed mice. No difference in platelet numbers was found between saline-treated diabetic and saline-treated non-diabetic mice. In diabetic mice exposed to DEP, the number of platelets was significantly decreased compared to saline-treated diabetic mice or DEP-treated non-diabetic mice.

In non-diabetic mice treated with DEP, the thrombotic occlusion time was significantly shortened compared to saline-treated non-diabetic mice. Similarly, the thrombotic occlusion time was significantly decreased in DEP-treated diabetic mice versus saline-treated diabetic mice. Interestingly, the degree of shortening in the occlusion time was significantly greater in DEP-exposed 
Figure 1 Effect of diesel exhaust particles (DEP) on leukocyte numbers (A), C-reactive protein (CRP, B) and 8-isoprostane (C) concentrations in plasma. The latter were measured $24 \mathrm{~h}$

following intratracheal instillation of DEP $(0.4 \mathrm{mg} / \mathrm{kg})$ or saline in non-diabetic and diabetic mice. Data are mean \pm SEM $(n=8)$.

diabetic mice compared to DEP-exposed non-diabetic mice (Figure 4B).

Effect of DEP on platelet aggregation in whole blood in vitro

Figure 5 illustrates that low concentrations of DEP $(0.25-1 \mu \mathrm{g} / \mathrm{ml}$ blood) caused platelet aggregation in a dose-dependent manner. In non-diabetic mouse blood,

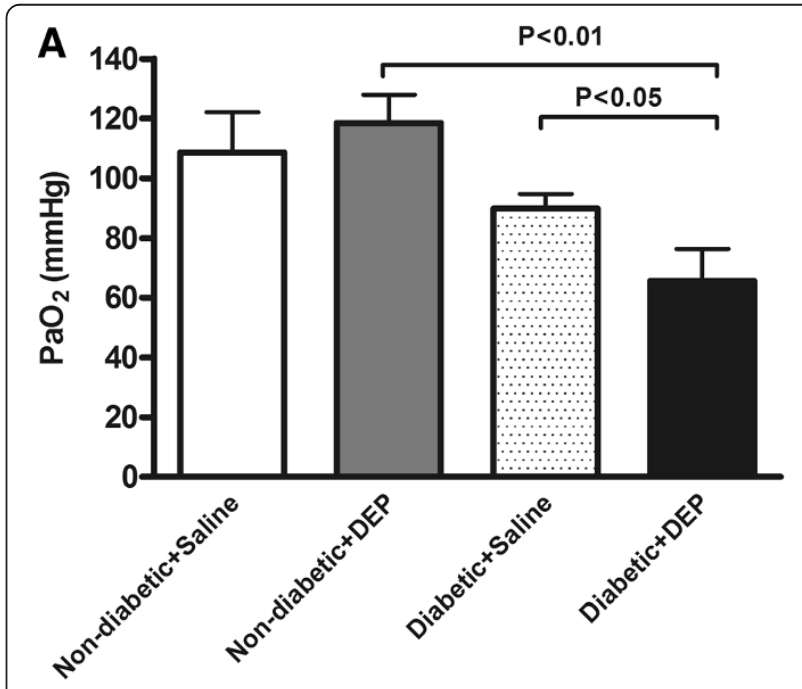

B
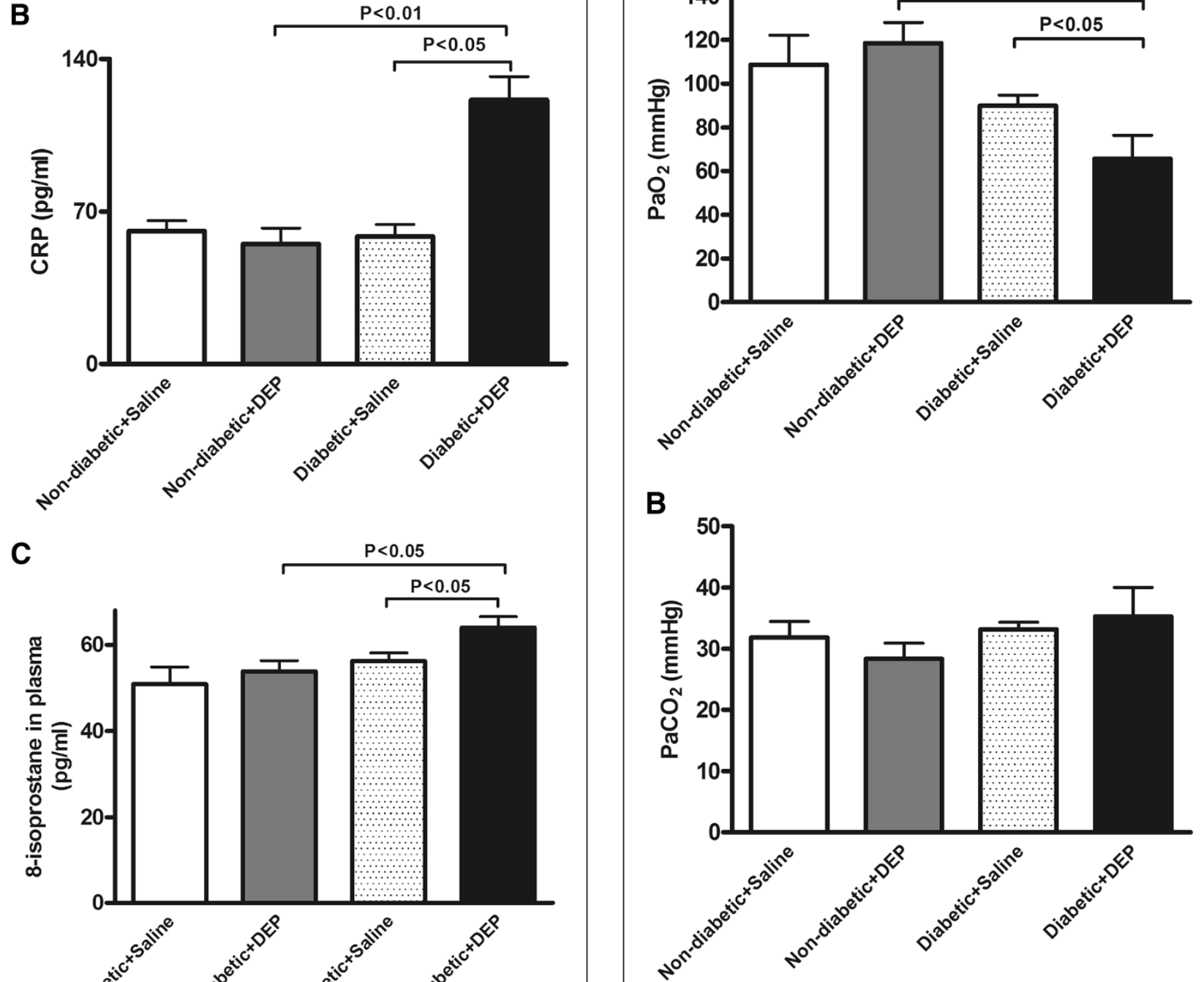

Figure 2 Effect of diesel exhaust particles (DEP) on arterial $\mathrm{PO}_{2}$ (A) and $\mathrm{PCO}_{2}$ (B). The latter were measured $24 \mathrm{~h}$ following

intratracheal instillation of DEP $(0.4 \mathrm{mg} / \mathrm{kg})$ or saline in non-diabetic and diabetic mice. Data are mean \pm SEM $(n=8)$. 


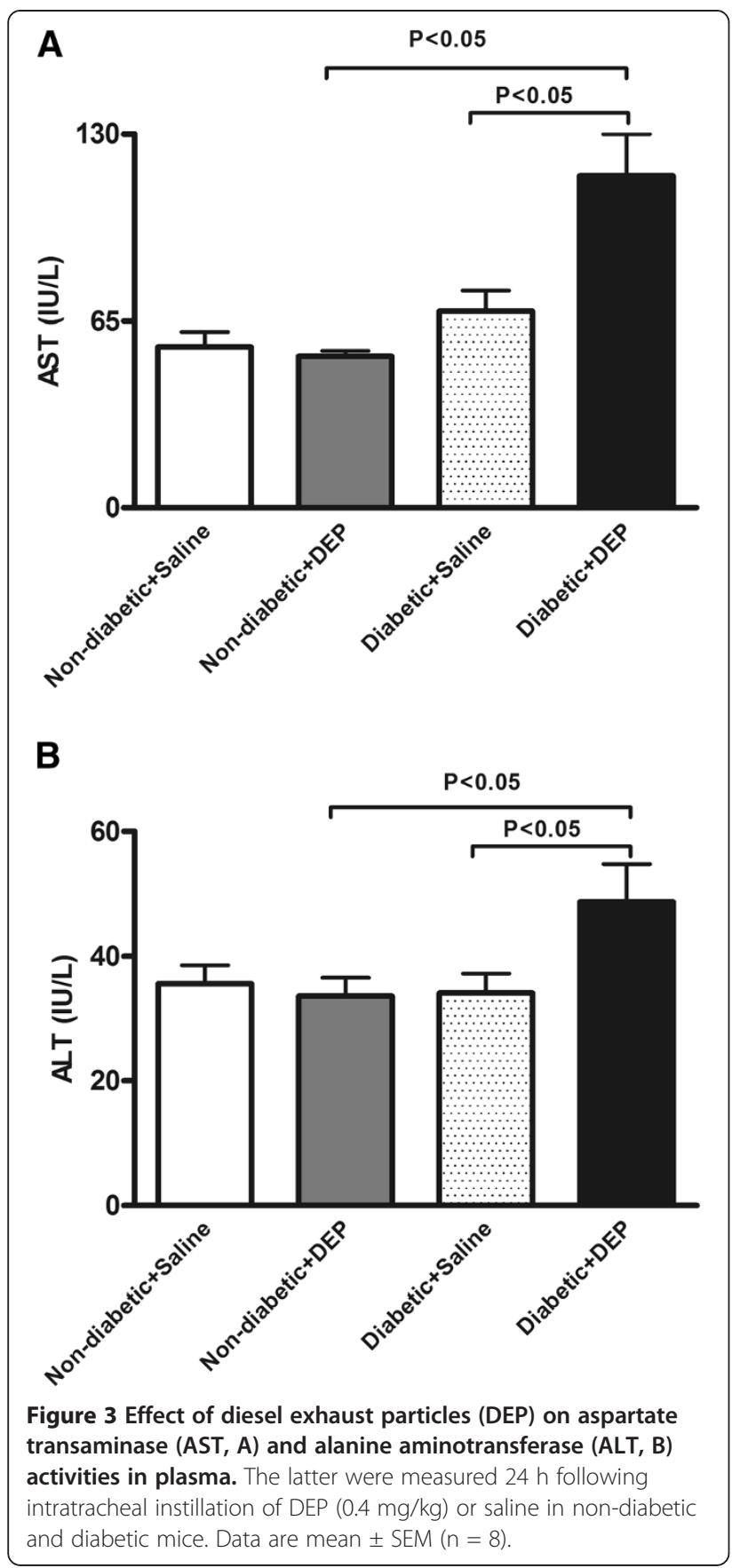

the effect was significant at concentrations of $1 \mu \mathrm{g} / \mathrm{ml}$ $(\mathrm{P}<0.005)$. In diabetic mouse blood, a clear dosedependent effect of DEP on platelet aggregation was observed. The effect of DEP on platelet aggregation was significant at $0.25(\mathrm{P}<0.05), 0.5(\mathrm{P}<0.0001)$ and 1 $\mu \mathrm{g} / \mathrm{ml}(\mathrm{P}<0.0001)$. Moreover, in diabetic blood, the effect observed at $1 \mu \mathrm{g} / \mathrm{ml}$ was statistically significant $(\mathrm{P}<0.0001)$ compared with the same dose in nondiabetic mouse blood.

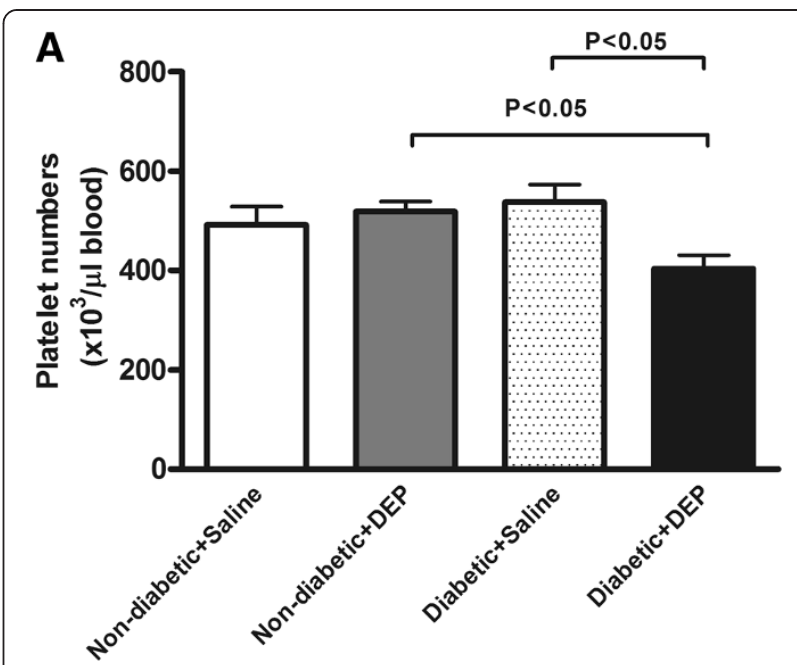

B

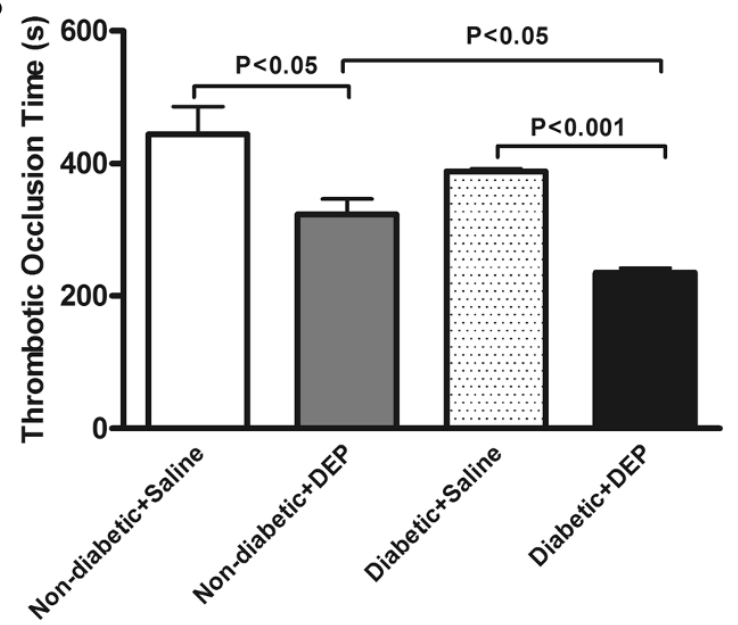

Figure 4 Effect of diesel exhaust particles (DEP) on circulating platelet numbers (A) and thrombotic occlusion time in pial arterioles (B). The latter were measured $24 \mathrm{~h}$ following intratracheal instillation of DEP $(0.4 \mathrm{mg} / \mathrm{kg})$ or saline in non-diabetic and diabetic mice. Data are mean \pm SEM $(n=8)$.

Effect of DEP on plasma concentrations of von Willebrand factor (vWF) and total plasminogen activator inhibitor-1 (PAI-1)

Figure 6A shows that DEP exposure in both diabetic and non-diabetic mice causes a significant increase of PAI-1 concentration compared to their respective controls. PAI-1 was increased in a greater fashion in the non-diabetic + saline group versus non-diabetic + DEP group $(+35 \%, \mathrm{P}<0.001)$ compared to diabetic + saline versus diabetic + DEP $(+21 \%, P<0.01)$. The increase of PAI-1 in diabetic mice exposed to DEP was significantly higher compared to non-diabetic mice exposed to DEP $(+19 \%, \mathrm{P}<0.01)$.

The plasma concentration of vWF was not significantly affected following DEP exposure in non-diabetic mice. However, in diabetic mice exposed to DEP, vWF 


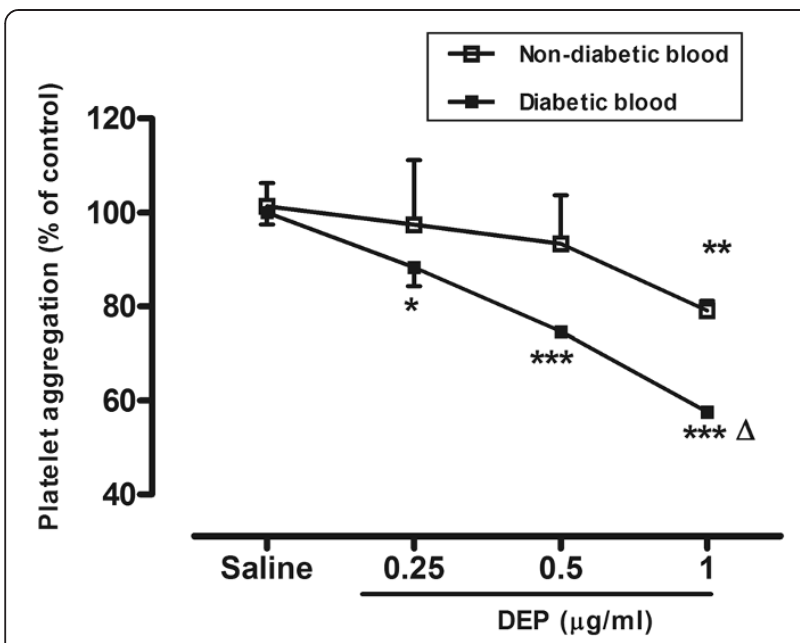

Figure 5 Direct in vitro effect of diesel exhaust particles (DEP) on platelet aggregation in whole blood of untreated non-diabetic and diabetic mice. Platelet aggregation in untreated non-diabetic and diabetic mouse whole blood 3 min after the addition of saline or DEP $(0.25-1 \mathrm{\mu g} / \mathrm{ml})$ was assessed. The degree of platelet aggregation following DEP exposure was expressed in percent of control (saline-treated diabetic or non-diabetic blood). Data are mean \pm SEM $(n=3-5)$. *: $P<0.05$ compared with saline-treated blood within the same group. ${ }^{* *}: P<0.005$ compared with saline-treated blood within the same group. ${ }^{* * *}: P<0.0001$ compared with saline-treated blood within the same group. ${ }^{\Delta}: \mathrm{P}<0.0001$ between diabetic and non-diabetic groups for the same given DEP concentration.

significantly increased compared to saline-exposed diabetic mice or DEP-exposed non-diabetic mice (Figure 6B).

\section{Discussion}

In the present study, we showed an increased cardiovascular vulnerability of diabetic mice to particulate air pollution. We found an aggravation of the impact of acute exposure to DEP in diabetic mice substantiated by increase of systemic inflammation (leukocytosis and CRP), oxidative stress (8-isoprostane), hypoxemia, hepatotoxicity and acceleration of coagulation comprising thrombosis in vivo, platelet aggregation in vitro, and the increase in plasma concentrations of PAI-1 and vWF.

In the present study, we used a pertinent animal model of type 1 diabetes, i.e. STZ-induced diabetes in mice $[11,13]$ and assessed the acute effects of a relevant type of pollutant particles, namely DEP. The dose of DEP used here $0.4 \mathrm{mg} / \mathrm{kg}(10 \mu \mathrm{g} /$ mouse $)$ is lower than the dose previously tested, i.e. $0.5 \mathrm{mg} / \mathrm{kg}$ (15 $\mu \mathrm{g} / \mathrm{mouse})$ or $1 \mathrm{mg} / \mathrm{kg}$ (30 $\mu \mathrm{g} /$ mouse) because we hypothesized that the effects of DEP would be aggravated in STZ-induced type 1 diabetes in mice. DEP was given to mice by i.t. instillation because it provides more accurate dosing, given that mice are nose breathers that filter most inhaled particles [14]. In 2002, the United States Environmental Protection Agency reported a range of maximal city $\mathrm{PM}_{10}$ concentrations between 26 and $534 \mu \mathrm{g} / \mathrm{m}^{3}$ [15]. Several

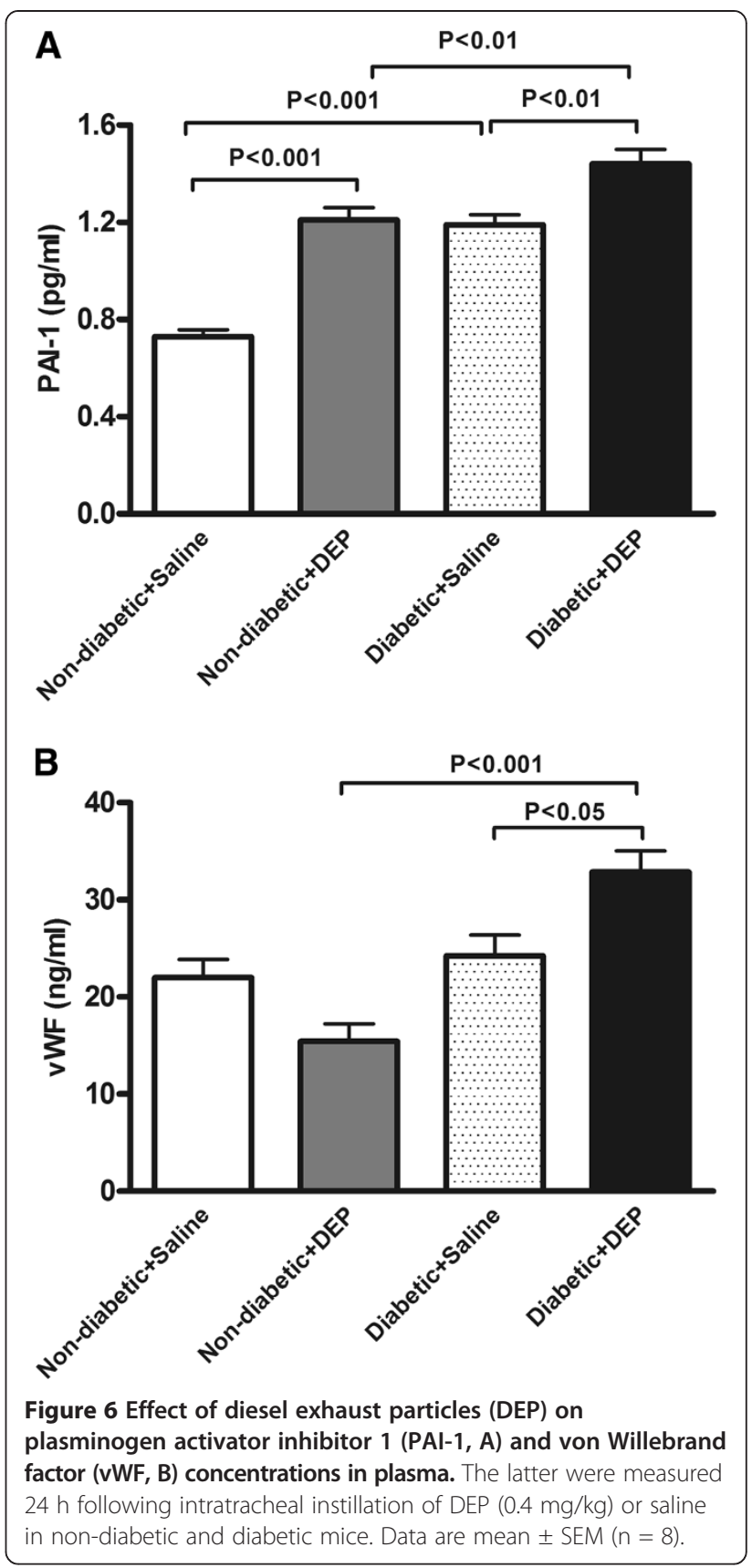

large cities in the world have much higher levels of $\mathrm{PM}_{10}$, with annual averages of 200 to $600 \mu \mathrm{g} / \mathrm{m}^{3}$ and peak concentrations frequently exceeding $1,000 \mu \mathrm{g} / \mathrm{m}^{3}$ [16]. Using the highest value in the United States and assuming a minute ventilation of $6 \mathrm{l} / \mathrm{min}\left(\sim 8.6 \mathrm{~m}^{3}\right.$ over 24 hours $)$ for a healthy adult at rest, the total dose of PM inhaled over 24 hours would be 4,614 $\mu \mathrm{g}$ [17]. Exposure of a human to a daily dose of 4,614 $\mu \mathrm{g}$ of PM would correspond to more than $35 \mu \mathrm{g}$ of PM exposure for a mouse (25 grams in size) with minute ventilation of $35-50 \mathrm{ml} / \mathrm{min}$ [17]. The dose we tested here $(10 \mu \mathrm{g} /$ mouse $)$ is lower than the comparative human dose of $\pm 35 \mu \mathrm{g} /$ mouse reported by Mutlu et al. [17]. 
Our data show that in non-diabetic mice, at the dose and regimen studied, DEP did not affect the number of leukocytes or the CRP concentration in plasma. Previously, $24 \mathrm{~h}$ post-exposure to higher doses of DEP, i.e. $15 \mu \mathrm{g} /$ mouse $(0.5 \mathrm{mg} / \mathrm{kg})$ or $30 \mu \mathrm{g} / \mathrm{mouse}(1 \mathrm{mg} / \mathrm{kg})$, we found no increase in the number of leukocytes $[18,19]$. No significant differences were observed between control diabetic and non-diabetic mice. Interestingly, DEP exposure induced a leukocytosis and a significant increase of CRP, indicating the occurrence of systemic inflammation. Our finding corroborate epidemiological studies that have reported positive associations between air pollution and indicators of systemic inflammation such as leukocyte numbers, interleukin 6 and CRP $[3,20]$. Remarkably, it has been reported that these associations were stronger and most consistent in individuals with diabetes [3]. We have recently reported that repeated exposure to DEP causes an increase in CRP concentration and that the pre-treatment with the anti-inflammatory and antioxidant curcumin returned the CRP concentrations to control levels [21].

We have recently demonstrated that $24 \mathrm{~h}$ following their i.t. instillation, DEP (0.5 and $1 \mathrm{mg} / \mathrm{kg})$ caused pulmonary and systemic oxidative stress responsible for systemic inflammation, and that the pretreatment with a cysteine prodrug L-2-oxothiazolidine-4-carboxylic acid abrogated these effects through its ability to balance oxidant-antioxidant status [18]. In the present study, as a marker for oxidative stress, we selected to measure the plasma concentrations of 8-isoprostane. Isoprostanes are a family of eicosanoids of nonenzymatic origin, produced by the random oxidation of tissue phospholipids by oxygen radicals. Elevated levels of isoprostanes have been found in serum, plasma, and urine of heavy smokers [22] and lung tissue of mice expose to carbon nanoparticles [23]. Here, we found that plasma 8-isoprostane concentrations were significantly increased after the pulmonary exposure to DEP in diabetic mice versus diabetic mice exposed to saline or non-diabetic mice exposed to DEP. It is well-established that oxidative stress plays a key role in the pathogenesis of of diabetes mellitus [24]. Diabetic patients usually have significantly elevated concentrations of 8-OHdG in their serum and decreased levels of glutathione [24]. Our data are in agreement with previous findings which reported that $\mathrm{PM}_{2.5}$ exposure causes aggravation of plasma oxidative stress in STZ-diabetic rats compared to nondiabetic rats [11].

While $\mathrm{PaCO}_{2}$ was not affected by DEP in both diabetic and non-diabetic mice, the $\mathrm{PaO}_{2}$ was significantly decreased in diabetic mice exposed to DEP compared to diabetic mice exposed to saline or non-diabetic mice exposed to DEP. We recently demonstrated that DEP exposure in hypertensive mice significantly decreased the $\mathrm{PaO}_{2}$ compared with DEP-treated normotensive mice. Moreover, using a rat model of cisplatin-induced acute renal failure, we have recently shown a decrease in $\mathrm{PaO}_{2}$ following DEP exposure [25]. Our findings are in agreement with epidemiological studies that suggested that pollution may result in hypoxemia and that these effects might be most relevant in older and sicker individuals $[26,27]$.

In non-diabetic mice, DEP administration did not affect the plasma activities of AST and ALT compared to saline-exposed mice. No difference in the enzyme activities was found between saline-treated diabetic and saline-treated non-diabetic mice. Remarkably, the AST and ALT activities were increased in DEP-exposed diabetic mice compared to diabetic mice exposed to saline or DEP-exposed non-diabetic mice, indicating that DEP causes tissue damage in diabetic mice. Exposure to $\mathrm{PM}_{2.5}$ in healthy mice did not affect AST and ALT activities [28]. However, it has been reported that pulmonary exposure of obese diabetic mice to DEP causes an increase in the activities of AST, ALT, the ratio of liver weight, and the magnitude of fatty change of the liver in histology [29]. Epidemiological and clinical studies are needed to verify the occurrence of liver injury following the exposure to particulate air pollution in susceptible population.

A strong epidemiologic association has been observed between increased levels of PM and hospitalizations for heart disease among those who had diabetes compared with those who did not [5]. The risk of coronary heart disease, stroke, and peripheral arterial disease is increased in persons with diabetes [30]. Several experimental studies have reported that exposure to particles causes prothrombotic effects in the ear vein of rats [31], femoral vein and artery of hamsters [32-35] carotid artery of mice [17] and pial venule or arterioles of mice $[18,36]$. Our data confirms the occurrence of prothrombotic effects following the exposure to DEP in non-diabetic mice compared to saline-treated non-diabetic mice. Similarly, we found a shortening in the thrombotic occlusion time in diabetic mice exposed to DEP compared to those exposed to saline. Interestingly, the degree of shortening in the thrombotic occlusion time was significantly greater DEP-exposed diabetic mice compared to DEP-exposed non-diabetic mice. Recently, we reported an aggravation of thrombotic events in hypertensive mice [19].

Along with the potentiation of prothrombotic effect in diabetic mice exposed to DEP, we found a significant decrease in platelet numbers in DEP-exposed diabetic mice compared to DEP-exposed non-diabetic mice or saline-exposed diabetic mice, this is indicative of platelet activation in vivo. A decrease of platelet numbers following exposure to particles has been reported from experimental and clinical studies [18,37].

It has been suggested that inhaled particles may lead to systemic inflammatory response through the release of inflammatory mediators and oxidative stress within the 
lungs and/or systemically [1,38]. Additional experiments showed that air pollution exposure is associated with rapid changes in autonomic nervous system balance, favouring sympathetic nervous system activation and parasympathetic withdrawal $[1,38]$. Other lines of evidence also suggest that nanoparticulate inhalation can rapidly translocate from through the alveolar capillary barrier and directly affect the cardiovascular system [1,38-40]. Because arteriolar thrombosis measured in vivo in our model depends mainly on the intensity of the vascular lesion and subsequent platelet recruitment and aggregation, we wanted to test the direct effect of DEP on platelet aggregation in whole blood of diabetic and non-diabetic mice in vitro. We, and others, have previously reported that DEP cause platelet aggregation $[36,41]$. Our in vitro observations confirmed the occurrence of platelet aggregation following the addition of DEP. Clearly, an aggravated effect was observed in diabetic mouse blood with dose-dependent and significant graded effects at $0.25,0.5$ and $1 \mu \mathrm{g} / \mathrm{ml}$ DEP. Interestingly, in diabetic blood, the effect observed at $1 \mu \mathrm{g} / \mathrm{ml}$ was statistically significant compared with the same dose in non-diabetic mouse blood. This in vitro finding corroborates our in vivo observation. Such observation has, as far as we are aware, never been reported before. Our data corroborate a recent human study which reported that PM exposure was associated with a change in platelet function toward a greater prothrombotic tendency in diabetic patients [42].

Exposure to DEP in both diabetic and non-diabetic mice caused a significant increase of PAI-1 concentration compared to their respective controls. However, PAI-1 was increased in a greater fashion in the non-diabetic + saline group versus non-diabetic + DEP $(+35 \%)$ group compared to diabetic + saline versus diabetic $+\mathrm{DEP}(+21 \%)$ mice. This difference can be explained by the fact that the concentration of PAI-1 in diabetic + saline group was significantly increased compared to non-diabetic + saline group. This finding corroborates the study of Tagher et al. [43] who found that PAI-1 concentration was significantly higher in patient with type 1 diabetes compared to healthy controls. We found a significant increase of circulating PAI-1 in diabetic mice exposed to DEP compared to diabetic mice exposed to saline or non-diabetic mice exposed to DEP. Raised concentrations of circulating PAI-1 have been acknowledged as an independent risk factor for the development of ischemic cardiovascular events $[44,45]$. The concurrent increase of plasma PAI- 1 and decrease of $\mathrm{PaO}_{2}$ that we observed corroborate the finding of pinsky et al. [46] who demonstrated that enhanced expression of PAI-1 is an important mechanism suppressing fibrinolysis under conditions of low oxygen tension. We recently reported that repeated exposure to DEP in healthy mice caused an increase of plasma PAI-1 concentration, and another study showed an increase in PAI-1 mRNA and protein concentrations in lung and adipose tissue of mice treated with PM [47]. Moreover, Erdely et al. [48] showed that pulmonary exposure to carbon nanotube increased the active form as well as total PAI- 1 in the circulation. We also found an increase of vWF in DEP-treated diabetic mice compared to saline-treated diabetic mice or DEP-treated non-diabetic mice. vWF reflects endothelial cell release and probably vascular reactivity. Vascular reactivity could results from the oxidative stress or direct effects of DEP that have presumably translocated into the systemic circulation. Moreover, vWF can mediate platelet adhesion to damaged endothelium, this could explain at least partly the observed exaggerated prothrombotic effects of DEP in diabetic mice. Elevated levels of vWF were observed in association with increased concentrations of particulate matter in patients with coronary heart disease [49]. In healthy mice, increased vWF expression on hepatic endothelium was detected after intraarterial administration of nanoparticles [50].

Collectively, our data show an aggravation of various systemic and coagulation endpoints in vivo and in vitro in diabetic mice acutely exposed to DEP compared to non-diabetic mice exposed to DEP or diabetic mice exposed to saline. These exacerbations could be ascribed to the increase of systemic oxidative stress and inflammation observed particularly in diabetic mice exposed to DEP (Figure 1). Indeed, both oxidative stress and inflammation were reported to play a critical role in the cardiovascular effects of particulate air pollution $[1,18,36]$ and diabetes [51]. Nevertheless, further studies are required clarify the mechanisms underlying the effect of type 1 diabetes and DEP on the cardiovascular system and whether the observed effects are strain-dependent. A murine strain differences in airway inflammation caused by DEP has been previously reported [52].

We conclude that systemic and coagulation events are aggravated in type 1 diabetic mice acutely exposed to DEP. Our findings provide possible plausible explanation for the exacerbation of cardiovascular morbidity accompanying particulate air pollution in diabetic patients. Additional experiments are needed to evaluate the chronic effect of DEP on type 1 diabetes and determine whether the observed effects are related to the DEP-associated components or by particles themselves.

\section{Material and methods \\ DEP}

The DEP (SRM 2975) were obtained from the National Institute of Standards and Technology (NIST, Gaithersburg, MD, USA), and were suspended in sterile saline $(\mathrm{NaCl} 0.9 \%)$ containing Tween 80 (0.01\%). To minimize aggregation, particle suspensions were always sonicated (Clifton Ultrasonic Bath, Clifton, New Jersey, USA) for 15 min and vortexed before their dilution and prior to intratracheal (i.t.) administration. Control animals received saline containing Tween 80 (0.01\%). 
DEP suspension that we used here has been previously analyzed by transmission electron microscopy [53,54]. This has revealed the presence numerous small aggregates of carbonaceous particles, and substantial amount of ultrafine (nano)-sized particle (less than $100 \mathrm{~nm}$ ) aggregates were seen. Most of the observed aggregates were $<1 \mu \mathrm{m}$ in the largest diameter $[53,54]$.

The endotoxin concentration in the DEP solution and saline used was quantified, as described by the manufacturer, by chromogenic Limulus Amebocyte Lysate (Pierce, Rockford, IL) test. The concentration was lower than the detection limit $(0.1 \mathrm{EU} / \mathrm{ml})$ in the saline and DEP solutions.

\section{Animals and treatments}

This project was reviewed and approved by the Institutional Review Board of the United Arab Emirates University, College of Medicine and Health Sciences, and experiments were performed in accordance with protocols approved by the Institutional Animal Care and Research Advisory Committee.

Male TO mice (HsdOla:TO, Harlan, UK) were housed in light (12-h light:12-h dark cycle) and temperaturecontrolled $\left(22 \pm 1^{\circ} \mathrm{C}\right)$ rooms. They had free access to commercial laboratory chow and were provided tap water ad libitum.

Type 1 diabetes mellitus was induced in male TO mice (6 to 8 weeks old) by intraperitoneal (i.p.) injection of $200 \mathrm{mg} / \mathrm{kg}$ body weigh STZ (Sigma Chemical, St. Louis, MO) [55,56]. Tail vein blood glucose samples were measured before and during 4 weeks after injection to ensure induction of diabetes. The non-diabetic (control) mice were injected i.p. with the vehicle ( $0.1 \mathrm{~mol} / \mathrm{l}$ citrate buffer, $\mathrm{pH} 4.5)$. Four-weeks post-STZ injection, mice were anesthetized with sodium pentobarbital (60 mg/kg, i.p.), placed supine with extended neck on an angled board. A Becton Dickinson 24 Gauge cannula was inserted via the mouth into the trachea. The DEP suspensions $(0.4 \mathrm{mg} / \mathrm{kg})$ or saline-only were instilled intratrachealy (i.t.) $(50 \mu \mathrm{l})$ via a sterile syringe and followed by an air bolus of $50 \mu \mathrm{l}$ to diabetic or non-diabetic mice.

\section{Blood collection and analysis}

$24 \mathrm{~h}$ after the the i.t. administration of either saline or DEP, the animals were anesthetized, as described above, and blood was drawn from the inferior vena cava in EDTA (4\%). A sample was used for platelets and white blood cells counting using an ABX VET ABC Hematology Analyzer with a mouse card (ABX Diagnostics, Montpellier, France). The remaining blood was centrifuged at $4^{\circ} \mathrm{C}$ for $15 \mathrm{~min}$ at $900 \mathrm{~g}$ and the plasma samples were stored at $-80^{\circ} \mathrm{C}$ until further analysis.

\section{Determination of CRP, 8-isoprostane, ALT, AST, vWF and total PAI-1 levels in plasma}

The concentrations of CRP (Uscn Life Science Inc, Wuhan, China), 8-isoprostane (Cayman Chemicals, Michigan, USA), PAI-1 (Molecular Innovation, Southfield, MI, USA) and vWF (Uscn Life Science Inc, Wuhan, China) were determined using ELISA Kits. The activities of AST and ALT were measured using standard laboratory methods with LX20 multiple automated analyser (Beckman Coulter, CA, USA).

\section{Arterial $\mathrm{PO}_{2}$ and $\mathrm{PCO}_{2}$ analysis}

Arterial blood gases were measured in separate animals following the protocol described above. Immediately after the anesthesia, arterial blood was obtained via the abdominal aorta with a heparinized 24-gauge needle. Analysis was performed immediately after collection with an OPTI CCA-TS blood gas analyzer (OPTI Medical, Roswell, GA, USA).

\section{Experimental pial cerebral arterioles thrombosis model}

In a separate experiment, in vivo pial arteriolar thrombogenesis was assessed 24 hours after the i.t. instillation of either DEP or saline, according to a previously described technique $[18,36]$. Briefly, the trachea was intubated after induction of anesthesia with urethane (1 mg/g body weight, i.p.), and a $2 \mathrm{~F}$ venous catheter (Portex, Hythe, UK) was inserted in the right jugular vein for the administration of fluorescein (Sigma, St. Louis, MO, USA). After that, a craniotomy was first performed on the left side, using a microdrill, and the dura was stripped open. Only untraumatized preparations were used, and those showing trauma to either microvessels or underlying brain tissue were discarded. The animals were then placed on the stage of a fluorescence microscope (Olympus, Melville, NY, USA) attached to a camera and DVD recorder. A heating mat was placed under the mice and body temperature was raised to $37^{\circ} \mathrm{C}$, as monitored by a rectal thermoprobe connected to a temperature reader (Physitemp Instruments, NJ, USA). The cranial preparation was moistened continuously with artificial cerebrospinal fluid of the following composition (mM): $\mathrm{NaCl} 124, \mathrm{KCl} 5$, $\mathrm{NaH}_{2} \mathrm{PO}_{4} 3, \mathrm{CaCl}_{2} 2.5, \mathrm{MgSO}_{4} .4, \mathrm{NaHCO}_{3} 23$ and glucose 10, $\mathrm{pH}$ 7.3-7.4. A field containing arterioles $15-20 \mu \mathrm{m}$ in diameter was chosen. Such a field was taped prior to and during the photochemical insult, which was carried out by injecting fluorescein $(0.1 \mathrm{ml} /$ mouse of $5 \%$ solution $)$ via the jugular vein, which was allowed to circulate for 30-40 sec. The cranial preparation was then exposed to stabilized mercury light. The combination produces endothelium injury of the arterioles. This, in turn, causes platelets to adhere at the site of endothelial damage and then aggregate. Platelet aggregates and thrombus formation grow in size until complete vascular occlusion. The 
time from the photochemical injury until full vascular occlusion (time to flow stop) in arterioles were measured in seconds. At the end of the experiments, the animals were euthanized by an overdose of urethane.

\section{Platelet aggregation in mouse whole blood}

The platelet aggregation assay in whole blood was performed, with slight modification, as described before [57]. After anesthesia, blood from untreated diabetic and non-diabetic mice was withdrawn from the inferior vena cava and placed in citrate (3.2\%), and 100- $\mu$ l aliquots were added to the well of a Merlin coagulometer (MC 1 VET; Merlin, Lemgo, Germany). The blood samples were incubated at $37.2^{\circ} \mathrm{C}$ with either saline (control) or DEP $(0.25-1 \mu \mathrm{g} / \mathrm{ml})$ for $3 \mathrm{~min}$, and then stirred for another $3 \mathrm{~min}$. At the end of this period, $25-\mu \mathrm{l} \mathrm{sam}$ ples were removed and fixed on ice in $225 \mathrm{ml}$ cellFix (Becton Dickinson). After fixation, single platelets were counted in a VET ABX Micros with mouse card (ABX, Montpellier, France). The degree of platelet aggregation following DEP exposure was expressed as a \% of control (saline-treated blood).

\section{Statistics}

Data were expressed as means \pm SEM, and were analyzed with GraphPad Prism Version 4.01 for Windows software (Graphpad Software Inc., San Diego, USA). For the in vivo results, comparisons between the four groups were performed by analysis of variance ANOVA, followed by Newman-Keuls multiple-range tests. For the in vitro platelet aggregation data, comparison was performed using unpaired student's t-test. $\mathrm{P}$ values $<0.05$ are considered significant.

\section{Competing interests}

The authors declare that they have no competing financial interests.

\section{Authors' contributions}

AN designed, planned, supervised all the experiments and wrote the article. DS and JY preformed the experiments. BHA contributed in the design of the study and wrote the article. All authors have read and approved the manuscript.

\section{Acknowledgements}

The authors would like to thank Mrs. S. Zia, Mrs. S. Beegam and Ms. P. Yuvaraju for their technical help.

This work was supported by funds of the Sheikh Hamdan Foundation for Medical Research (MRG-39/2007-2008) and the College of Medicine and Health Sciences grants.

\section{Author details}

'Departments of Physiology, College of Medicine and Health Sciences, United Arab Emirates University, P.O. Box 17666, Al Ain, Unite Arab Emirates. ${ }^{2}$ Departments of Internal Medicine, College of Medicine and Health Sciences, United Arab Emirates University, P.O. Box 17666, Al Ain, United Arab Emirates. ${ }^{3}$ Department of Pharmacology and Clinical Pharmacy, College of Medicine \& Health Sciences, Sultan Qaboos University, P O Box 35Muscat 123, Al-Khod, Sultanate of Oman.

\section{References}

1. Brook RD, Rajagopalan S, Pope CA, Brook JR, Bhatnagar A, Diez-Roux AV, et al: Particulate matter Air pollution and cardiovascular disease an update to the scientific statement from the american heart association. Circulation 2010, 121:2331-2378.

2. Franchini M, Mannucci PM: Thrombogenicity and cardiovascular effects of ambient air pollution. Blood 2011, 118:2405-2412.

3. Dubowsky SD, Suh H, Schwartz J, Coull BA, Gold DR: Diabetes, obesity, and hypertension may enhance associations between air pollution and markers of systemic inflammation. Environ Health Perspect 2006, 114:992-998.

4. O'Neill MS, Veves A, Zanobetti A, Sarnat JA, Gold DR, Economides PA, et al: Diabetes enhances vulnerability to particulate air pollution - Associated impairment in vascular reactivity and endothelial function. Circulation 2005, 111:2913-2920.

5. Zanobetti A, Schwartz J: Cardiovascular damage by airborne particles: are diabetics more susceptible? Epidemiology 2002, 13:588-592.

6. Olokoba AB, Obateru OA, Olokoba LB: Type 2 diabetes mellitus: a review of current trends. Oman Med J 2012, 27:269-273.

7. Targher G, Chonchol M, Zoppini G, Franchini M: Hemostatic disorders in type 1 diabetes mellitus. Semin Thromb Hemost 2011, 37:58-65.

8. Sun Q, Yue P, Deiuliis JA, Lumeng CN, Kampfrath T, Mikolaj MB, et al: Ambient air pollution exaggerates adipose inflammation and insulin resistance in a mouse model of diet-induced obesity. Circulation 2009, 119:538-546.

9. Xu X, Liu C, Xu Z, Tzan K, Zhong M, Wang A, et al: Long-term exposure to ambient fine particulate pollution induces insulin resistance and mitochondrial alteration in adipose tissue. Toxicol Sci 2011, 124:88-98.

10. Yan YH, Chou CC, Lee CT, Liu JY, Cheng TJ: Enhanced insulin resistance in diet-induced obese rats exposed to fine particles by instillation. Inhal Toxicol 2011, 23:507-519.

11. Lei YC, Hwang JS, Chan CC, Lee CT, Cheng TJ: Enhanced oxidative stress and endothelial dysfunction in streptozotocin-diabetic rats exposed to fine particles. Environ Res 2005, 99:335-343.

12. Nemmar A, Al-Salam S, Subramaniyan D, Yasin J, Yuvaraju P, Beegam S, et al: Influence of experimental type 1 diabetes on the pulmonary effects of diesel exhaust particles in mice. Toxicol Lett 2013, 217(2):170-176.

13. Wu KK, Huan Y: Streptozotocin-induced diabetic models in mice and rats. Curr Protoc Pharmacol 2008. Chapter 5: Unit 5.47. doi:10.1002/0471141755. ph0547s40.

14. Driscoll KE, Costa DL, Hatch G, Henderson R, Oberdorster G, Salem H, et al: Intratracheal instillation as an exposure technique for the evaluation of respiratory tract toxicity: uses and limitations. Toxicol Sci 2000, 55:24-35.

15. Brook RD, Franklin B, Cascio W, Hong YL, Howard G, Lipsett M, et al: Air pollution and cardiovascular disease - A statement for healthcare professionals from the expert panel on population and prevention science of the American Heart Association. Circulation 2004, 109:2655-2671.

16. U.N.Environment Program and WHO Report: Air pollution in the world's megacities. A report from the U.N.Environment programme and WHO. Environment 1994, 36:5-37.

17. Mutlu GM, Green D, Bellmeyer A, Baker CM, Burgess Z, Rajamannan N, et al: Ambient particulate matter accelerates coagulation via an IL-6-dependent pathway. J Clin Invest 2007, 117:2952-2961.

18. Nemmar A, Al Salam S, Dhanasekaran S, Sudhadevi M, Ali BH: Pulmonary exposure to diesel exhaust particles promotes cerebral microvessel thrombosis: protective effect of a cysteine prodrug 1-2-oxothiazolidine-4carboxylic acid. Toxicology 2009, 263:84-92.

19. Nemmar A, Zia S, Subramaniyan D, Fahim MA, Ali BH: Exacerbation of thrombotic events by diesel exhaust particle in mouse model of hypertension. Toxicology 2011, 285:39-45.

20. Riediker M, Cascio WE, Griggs TR, Herbst MC, Bromberg PA, Neas L, et al: Particulate matter exposure in cars is associated with cardiovascular effects in healthy young men. Am J Respir Crit Care Med 2004, 169:934-940.

21. Nemmar A, Subramaniyan D, Ali BH: Protective effect of curcumin on pulmonary and cardiovascular effects induced by repeated exposure to diesel exhaust particles in mice. PLoS One 2012, 7:e39554.

22. Chehne F, Oguogho A, Lupattelli G, Budinsky AC, Palumbo B, Sinzinger H: Increase of isoprostane 8-epi-PGF(2alpha)after restarting smoking. Prostaglandins Leukot Essent Fatty Acids 2001, 64:307-310.

23. Alessandrini F, Beck-Speier I, Krappmann D, Weichenmeier I, Takenaka S, Karg E, et al: Role of oxidative stress in ultrafine particle-induced exacerbation of allergic lung inflammation. Am J Respir Crit Care Med 2009, 179:984-991. 
24. Maritim AC, Sanders RA, Watkins JB III: Diabetes, oxidative stress, and antioxidants: a review. J Biochem Mol Toxicol 2003, 17:24-38.

25. Nemmar A, Al Salam S, Zia S, Al Husseni I, Ali BH: Diesel exhaust particles in the lung aggravate experimental acute renal failure. Toxicol Sci 2010, 113:267-277.

26. DeMeo DL, Zanobetti A, Litonjua AA, Coull BA, Schwartz J, Gold DR: Ambient air pollution and oxygen saturation. Am J Respir Crit Care Med 2004, 170:383-387.

27. Pope CA III, Verrier RL, Lovett EG, Larson AC, Raizenne ME, Kanner RE, et al: Heart rate variability associated with particulate air pollution. Am Heart J 1999, 138:890-899.

28. OToole TE, Hellmann J, Wheat L, Haberzettl P, Lee J, Conklin DJ, et al: Episodic exposure to fine particulate air pollution decreases circulating levels of endothelial progenitor cells. Circ Res 2010, 107:200-203.

29. Tomaru M, Takano H, Inoue K, Yanagisawa R, Osakabe N, Yasuda A, et al: Pulmonary exposure to diesel exhaust particles enhances fatty change of the liver in obese diabetic mice. Int J Mol Med 2007, 19:17-22.

30. Franchini M, Mannucci PM: Association between venous and arterial thrombosis: clinical implications. Eur J Intern Med 2012, 23:333-337.

31. Silva VM, Corson N, Elder A, Oberdorster G: The rat ear vein model for investigating in vivo thrombogenicity of ultrafine particles (UFP). Toxicol Sci 2005, 85:983-989.

32. Nemmar A, Hoylaerts MF, Hoet PHM, Dinsdale D, Smith T, Xu H, et al: Ultrafine particles affect experimental thrombosis in an in vivo hamster model. Am J Respir Crit Care Med 2002, 166:998-1004.

33. Nemmar A, Hoylaerts M, Hoet PH, Vermylen J, Nemery B: Size effect of intratracheally instilled ultrafine particles on pulmonary inflammation and vascular thrombosis. Toxicol Appl Pharmacol 2003, 186:38-45.

34. Nemmar A, Hoet PH, Dinsdale D, Vermylen J, Hoylaerts MF, Nemery B: Diesel exhaust particles in lung acutely enhance experimental peripheral thrombosis. Circulation 2003, 107:1202-1208.

35. Nemmar A, Hoet PHM, Vermylen J, Nemery B, Hoylaerts MF: Pharmacological stabilization of mast cells abrogates late thrombotic events induced by diesel exhaust particles in hamsters. Circulation 2004, 110:1670-1677.

36. Nemmar A, Al-Salam S, Zia S, Marzouqi F, Al-Dhaheri A, Subramaniyan D, et al: Contrasting actions of diesel exhaust particles on the pulmonary and cardiovascular systems and the effects of thymoquinone. Br J Pharmacol 2011, 164:1871-1882

37. Ruckerl R, Phipps RP, Schneider A, Frampton M, Cyrys J, Oberdorster G, et al: Ultrafine particles and platelet activation in patients with coronary heart disease - results from a prospective panel study. Part Fibre Toxicol 2007, 4:1

38. Vermylen J, Nemmar A, Nemery B, Hoylaerts MF: Ambient air pollution and acute myocardial infarction. J Thromb Haemost 2005, 3:1955-1961.

39. Nemmar A, Hoylaerts MF, Hoet PH, Nemery B: Possible mechanisms of the cardiovascular effects of inhaled particles: systemic translocation and prothrombotic effects. Toxicol Lett 2004, 149:243-253.

40. Ali BH, Al Moundhri MS, Tag EM, Nemmar A, Tanira MO: The ameliorative effect of cysteine prodrug L-2-oxothiazolidine-4-carboxylic acid on cisplatin-induced nephrotoxicity in rats. Fundam Clin Pharmacol 2007, 21:547-553.

41. Radomski A, Jurasz P, Alonso-Escolano D, Drews M, Morandi M, Malinski T, et al: Nanoparticle-induced platelet aggregation and vascular thrombosis. Br J Pharmacol 2005, 146:882-893.

42. Jacobs L, Emmerechts J, Mathieu C, Hoylaerts MF, Fierens F, Hoet PH, et al: Air pollution related prothrombotic changes in persons with diabetes. Environ Health Perspect 2010, 118:191-196.

43. Targher G, Bertolini L, Zoppini G, Zenari L, Falezza G: Increased plasma markers of inflammation and endothelial dysfunction and their association with microvascular complications in Type 1 diabetic patients without clinically manifest macroangiopathy. Diabet Med 2005, 22:999-1004.

44. Thogersen AM, Jansson JH, Boman K, Nilsson TK, Weinehall L, Huhtasaari F, et al: High plasminogen activator inhibitor and tissue plasminogen activator levels in plasma precede a first acute myocardial infarction in both men and women: evidence for the fibrinolytic system as an independent primary risk factor. Circulation 1998, 98:2241-2247.

45. Cesari M, Pahor M, Incalzi RA: Plasminogen activator inhibitor-1 (PAI-1): a key factor linking fibrinolysis and age-related subclinical and clinical conditions. Cardiovasc Ther 2010, 28:e72-e91.

46. Pinsky DJ, Liao H, Lawson CA, Yan SF, Chen J, Carmeliet P, et al: Coordinated induction of plasminogen activator inhibitor-1 (PAl-1) and inhibition of plasminogen activator gene expression by hypoxia promotes pulmonary vascular fibrin deposition. J Clin Invest 1998, 102:919-928.

47. Budinger GRS, Mckell JL, Urich D, Foiles N, Weiss I, Chiarella SE, et al: Particulate matter-induced lung inflammation increases systemic levels of PAl-1 and activates coagulation through distinct mechanisms. PLoS One 2011, 6(4):e18525.

48. Erdely A, Hulderman T, Salmen R, Liston A, Zeidler-Erdely PC, Schwegler-Berry D, et al: Cross-talk between lung and systemic circulation during carbon nanotube respiratory exposure. Potential biomarkers. Nano Lett 2009, 9:36-43.

49. Ruckerl R, Ibald-Mulli A, Koenig W, Schneider A, Woelke G, Cyrys J, et al: Air pollution and markers of inflammation and coagulation in patients with coronary heart disease. Am J Respir Crit Care Med 2006, 173:432-441.

50. Khandoga A, Stampfl A, Takenaka S, Schulz H, Radykewicz R, Kreyling W, et al: Ultrafine particles exert prothrombotic but not inflammatory effects on the hepatic microcirculation in healthy mice in vivo. Circulation 2004, 109:1320-1325.

51. Forbes JM, Cooper ME: Mechanisms of diabetic complications. Physiol Rev 2013, 93:137-188.

52. Miyabara $Y$, Yanagisawa $R$, Shimojo N, Takano H, Lim HB, Ichinose $T$, et al: Murine strain differences in airway inflammation caused by diesel exhaust particles. Eur Respir J 1998, 11:291-298.

53. Nemmar A, Al Maskari S, Ali BH, Al Amri IS: Cardiovascular and lung inflammatory effects induced by systemically administered diesel exhaust particles in rats. Am J Physiol Lung Cell Mol Physiol 2007, 292:L664-L670.

54. Nemmar A, Zia S, Subramaniyan D, Al-Amri I, Al Kindi MA, Ali BH: Interaction of diesel exhaust particles with human, rat and mouse erythrocytes in vitro. Cell Physiol Biochem 2012, 29:163-170.

55. Shiomi T, Tsutsui $H$, Ikeuchi M, Matsusaka H, Hayashidani S, Suematsu N, et al: Streptozotocin-induced hyperglycemia exacerbates left ventricular remodeling and failure after experimental myocardial infarction. J Am Coll Cardiol 2003, 42:165-172.

56. Denroche HC, Levi J, Wideman RD, Sequeira RM, Huynh FK, Covey SD, et al: Leptin therapy reverses hyperglycemia in mice with streptozotocin-induced diabetes, independent of hepatic leptin signaling. Diabetes 2011, 60:1414-1423.

57. Nemmar A, Melghit K, Ali BH: The acute proinflammatory and prothrombotic effects of pulmonary exposure to rutile $\mathrm{TiO} 2$ nanorods in rats. Exp Biol Med (Maywood) 2008, 233:610-619.

doi:10.1186/1743-8977-10-14

Cite this article as: Nemmar et al:: Impact of experimental type 1 diabetes mellitus on systemic and coagulation vulnerability in mice acutely exposed to diesel exhaust particles. Particle and Fibre Toxicology 2013 10:14

\section{Submit your next manuscript to BioMed Central and take full advantage of:}

- Convenient online submission

- Thorough peer review

- No space constraints or color figure charges

- Immediate publication on acceptance

- Inclusion in PubMed, CAS, Scopus and Google Scholar

- Research which is freely available for redistribution 